\title{
Non-rheumatic atrial fibrillation: warfarin or aspirin for all?
}

\author{
J Nolan, P Bloomfield
}

Stroke is the third most common cause of death in the United Kingdom after ischaemic heart disease and cancer. Disabled patients who survive an acute stroke place a great social and economic burden on the community-stroke prevention is therefore a priority. Cerebral infarction accounts for almost $80 \%$ of all first strokes. A significant proportion of these are embolic in origin and associated with atrial fibrillation. Anticoagulant and antiplatelet drugs may reduce the risk of stroke in such patients by preventing the formation of thrombus in the heart. What is the evidence that such treatment used as a primary preventive measure reduces the incidence of stroke in patients with atrial fibrillation? Which subgroups of patients are at high and low risk of stroke, who should be treated, and with what?

\section{Conventional indications for anticoagulant treatment in atrial fibrillation}

There is general agreement that patients with rheumatic or thyrotoxic atrial fibrillation and patients undergoing direct current cardioversion for fibrillation are at high risk of embolic stroke and that this risk is reduced by primary prevention with warfarin, ${ }^{1-6}$ although no adequate prospective randomised clinical trials have examined this in detail. Patients with a recent ischaemic stroke and atrial fibrillation may benefit from anticoagulation as a secondary preventive measure ${ }^{78}$; this issue is currently being prospectively investigated in the European Atrial Fibrillation Trial which may provide a clear answer when it reports in the near future.

\section{Non-rheumatic atrial fibrillation}

Atrial fibrillation occurring in the absence of rheumatic heart disease (non-rheumatic atrial fibrillation) is a common condition with an overall prevalence of $0.4 \%$ in the adult population. ${ }^{9}$ Its prevalence rises from $0.5 \%$ below the age of $60^{10}$ to $10 \%$ over the age of $75 .{ }^{11}$ Each year approximately $0.5 \%$ of people aged over 60 will develop non-rheumatic atrial fibrillation. In most cases non-rheumatic atrial fibrillation occurs in association with hypertension, ischaemic heart disease and congestive heart failure. ${ }^{1213}$

Non-rheumatic atrial fibrillation is clearly associated with an increased risk of stroke. In both the Framingham Study ${ }^{14}$ and a study of British civil servants ${ }^{15}$ there was a fivefold increase in the risk of stroke in such patients. The annual risk of stroke in patients with nonrheumatic atrial fibrillation is approximately $5 \%$. $^{1216}$

Subgroups of patients with non-rheumatic atrial fibrillation with different risk profiles for stroke can be identified. Chronic or paroxysmal atrial fibrillation occurring in patients below the age of 60 years in the absence of detectable cardiac disease (so called "lone atrial fibrillation") is associated with a low risk ${ }^{17-20}$ with stroke rates of $1.3 \%$ over a 15 year period (identical to that of an age and sex matched population). ${ }^{21}$ Paroxysmal atrial fibrillation may be associated with a lower risk of stroke than established atrial fibrillation, ${ }^{13}$ though this has not been well substantiated. The risk of stroke is higher in older patients and those with a history of previous thromboembolism, atrial fibrillation of recent onset, or associated cardiovascular disorders such as heart failure, cardiomyopathy, ischaemic heart disease, or hypertension. ${ }^{22-26}$ Patients with echocardiographic evidence of severe left ventricular dysfunction or left atrial enlargement are also at greater risk of stroke. ${ }^{27}$

\section{Pathophysiology of stroke associated with atrial fibrillation}

A large proportion of patients in recent studies of non-rheumatic atrial fibrillation had associated cardiac disorders (myocardial infarction, congestive heart failure, hypertension, mitral regurgitation, or calcification of the annulus of the mitral valve). Thrombus is known to develop in association with altered blood flow through the atria or in the left ventricle in such patients. Estimates from several clinical and necropsy series suggest that between $50 \%$ and $75 \%$ of ischaemic strokes in patients with non-rheumatic atrial fibrillation are due to emboli from the heart. ${ }^{28} 29$ Most nonembolic strokes in such patients are caused by coexistent atherosclerotic cerebrovascular diseases. Fibrin formation may be more active than platelet activation in the production of potential emboli in areas of stasis within dilated cardiac chambers, and these emboli may therefore be preventable with warfarin but not 
aspirin. Activation of platelets may be the dominant mechanism for the formation of emboli in patients who have turbulent flow over atherosclerotic plaques or across cardiac lesions such as calcified or thickened mitral valves, and both warfarin and aspirin may therefore be effective in these patients. ${ }^{30}$

\section{Anticoagulant treatment in non- rheumatic atrial fibrillation}

The potential benefit of anticoagulant treatment as primary prevention to reduce the risk of stroke in patients with non-rheumatic atrial fibrillation has been studied in four randomised prospective trials published in the past three years. ${ }^{31-34}$ All were terminated early on the recommendation of their data monitoring committees.

In the Copenhagen Atrial Fibrillation, Aspirin Anticoagulation (AFASAK) Study ${ }^{33}$ 1007 patients with established atrial fibrillation were randomised to receive warfarin (dose adjusted to give an international normalised ratio (INR) of 2.8-4.2), low dose aspirin (75 mg daily), or placebo. The mean age of the patients was 74 years; $8 \%$ had a history of myocardial infarction and $50 \%$ a history of heart failure. The primary end point of the trial was the occurrence of a thromboembolic event (all strokes, transient cerebral ischaemia, or systemic embolism). Most (78\%) of thromboembolic events that occurred were cerebral. Patients were followed up for at least two years and there was a significant $64 \%$ reduction in the annual thromboembolic event rate from 5.5\% per annum in the aspirin and placebo group to $2.0 \%$ per annum in the warfarin treated group.

In the Boston Area Anticoagulation Trial for Atrial Fibrillation (BAATAF) ${ }^{32} 420$ patients with atrial fibrillation (approximately one third of whom had paroxysmal atrial fibrillation) were randomised to receive warfarin (INR 1.5$2 \cdot 7$ ) or to a control group receiving no anticoagulants. The control group could be prescribed antiplatelet agents and almost half of the patients received aspirin. The mean age of the patients was 68 years: $13 \%$ had a history of myocardial infarction and $25 \%$ a history of heart failure. The primary end point was ischaemic stroke. After an average follow up period of $2 \cdot 2$ years there was a significant $86 \%$ reduction in the annual stroke rate from 3\% in the control group to $0.4 \%$ in the anticoagulated group.

In the Stroke Prevention in Atrial Fibrillation (SPAF) Study ${ }^{31} 1330$ patients (mean age 67 years) with atrial fibrillation (paroxysmal in one third of patients) were studied. Most patients $(71 \%)$ were men; $13 \%$ had a history of myocardial infarction and $19 \%$ a history of heart failure. There were 627 patients who were considered suitable for anticoagulation and they were randomised to receive warfarin (INR 2.0-4.5), aspirin (325 mg daily), or placebo. There were 703 patients who were not considered suitable for anticoagulation and they were randomised to receive aspirin (325 mg daily) or placebo. The primary end point of the study was the occurrence of a thromboembolic event (ischaemic stroke or systemic embolism) and once again most (96\%) of these events were cerebral. After a mean follow up period of 1.3 years there was a significant $67 \%$ reduction in the annual thromboembolic event rate in those receiving warfarin compared with those in the placebo group $(2.3 \%$ v $7 \cdot 4 \%$ per year $)$.

The Canadian Atrial Fibrillation Anticoagulation Study ${ }^{34}$ was similar in design to the BAATAF study. This study also showed a reduction in the incidence of stroke with warfarin treatment but the results did not reach statistical significance because after 378 patients had been randomised it was terminated when the positive findings in the above studies were reported.

Taken together, these large randomised prospective studies indicate that warfarin is effective in reducing the incidence of stroke and systemic embolism in patients with nonrheumatic atrial fibrillation.

The major danger of warfarin treatment is the risk of bleeding, which may counterbalance the beneficial effect of treatment. In both the SPAF and BAATAF studies the risk of major bleeding complications (requiring admission to hospital, blood transfusion, surgical intervention, or leading to death or permanent residual neurological deficit) was not increased by warfarin treatment. In the AFASAK study, however, with warfarin treatment the annual rate of major bleeding complications was $3.5 \%$ compared with $0.2 \%$ for aspirin and $0 \%$ for placebo. This difference may be due to several factors. Patients in the BAATAF study were treated with low intensity warfarin. Because lower levels of anticoagulation are associated with a lower risk of haemorrhagic complications ${ }^{35}$ this may explain the lower rate of bleeding complications in this study. Only about $10 \%$ of the patients eligible for the SPAF study were randomised, and this selection process may have produced a study group at low risk of bleeding complications. In the AFASAK study $40 \%$ of eligible patients were randomised. The use of high intensity warfarin treatment in an unselected population may explain the increased rate of major bleeding complications in the AFASAK study compared with the SPAF and BAATAF study.

\section{Bleeding complications and control of anticoagulation}

The risks of bleeding complications reported in the studies of anticoagulation in non-rheumatic atrial fibrillation need to be compared with those reported from studies of anticoagulant use in other conditions. In a long-term evaluation of heart valve prostheses recently reported from our hospital ${ }^{36}$ the actuarial risk of bleeding severe enough to cause admission to hospital or blood transfusion was $18.6 \%$ at 12 years, producing an annual bleeding rate of $1.7 \%$ that is similar to that reported in the SPAF and BAATAF trials. In a similar trial from the Veterans Administration in the United States ${ }^{37}$ the risk of bleeding was almost 
three times greater-a finding almost certainly due (at least in part) to the difference between United States and United Kingdom practices for control of warfarin treatment. ${ }^{38}$ It has recently been recognised that commercially available thromboplastins used in the United States are less sensitive than those in use in the United Kingdom. This has resulted in greater degrees of anticoagulation and larger doses of warfarin being used in the past in the United States to achieve similar prothrombin ratios to those used in monitoring anticoagulant treatment in Europe. ${ }^{39}$ Recognition of this problem has led to the widespread use of the INR to control warfarin treatment in the United States. Because difficulties remain in the conversion factors used to translate locally derived prothrombin ratios the INR ranges of anticoagulation quoted in different studies may not be directly comparable. ${ }^{40}$ These differences are, however, quite small and it seems evident from the BAATAF trial that the beneficial effects of warfarin in non-rheumatic atrial fibrillation can be realised at a lower level of anticoagulation with an INR of 1.5-2.7. Furthermore in two recently published randomised trials in patients with prosthetic heart valves $^{41}{ }^{42}$ lower intensity treatment with warfarin was no less efficacious than higher intensity treatment and was associated with a lower incidence of bleeding problems. Warfarin is often held to be contraindicated in elderly patients. A recent overview of published clinical trials showed no relation between age and the risk of bleeding during warfarin treatment. ${ }^{43}$ Carefully controlled low intensity warfarin is safe, even in the elderly, provided there are no obvious contraindications.

\section{Is aspirin a viable alternative to warfarin?}

Aspirin is a safe and convenient alternative to warfarin and would be preferable if it was effective in reducing stroke in non-rheumatic atrial fibrillation. A daily dose of $75 \mathrm{mg}$ of aspirin had no beneficial effect in the AFASAK study. The BAATAF study was designed only to examine the efficacy of warfarin, and did not report on the effect of aspirin. In the SPAF study aspirin (325 mg daily) significantly reduced $(42 \%)$ the thromboembolic event rate from $6.3 \%$. to $3.6 \%$ per year compared with placebo. The results of the direct comparison of warfarin and aspirin in this study were not reported because of the small numbers of patients enrolled: but this comparison is continuing as SPAF II.

Aspirin did not significantly increase the number of haemorrhagic episodes compared with placebo in both the AFASAK and the SPAF studies. Antiplatelet treatment with aspirin in the dose range $75-325 \mathrm{mg}$ daily is clearly safer than warfarin anticoagulation. Aspirin may have been effective in the SPAF study and not the AFASAK study because of the higher dose used or because as previously noted the patients in the AFASAK study were older and had a higher incidence of associated cardiac disease.

\section{Conclusion}

Giving warfarin to $2-5 \%$ of the population over the age of 60 years and as many as $10 \%$ over the age of 75 to reduce the risk of stroke is a daunting prospect. The burden on general practice and anticoagulant clinics would be substantial. It is clear, however, that patients with sustained or paroxysmal non-rheumatic atrial fibrillation have an annual risk of stroke of about $5 \%$, and that this risk can be reduced by anticoagulation with warfarin without an excessive risk of haemorrhagic complications. Recent estimates indicate that for every 1000 patients with non-rheumatic atrial fibrillation warfarin treatment for one year would prevent between 15 and 50 episodes of ischaemic stroke or systemic embolism at a cost of approximately 4-6 episodes of major bleeding. ${ }^{44}$ The potential risks and benefits of treatment need to be carefully weighed for each individual patient. Patients at high risk of stroke (those aged over 60 years with a dilated left ventricle, a large' left atrium, coexistent heart failure, or ischaemic heart disease) and low risk of a bleeding complication stand to gain most from warfarin treatment. We believe that such patients who have no contraindications, and in whom management of anticoagulation is feasible should receive warfarin. Because warfarin given at a lower intensity of anticoagulation is effective and is likely to be associated with a lower incidence of haemorrhagic complications, a low intensity regimen, aiming for an INR of $1 \cdot 5-2 \cdot 7$, should be used.

Patients below the age of 60 with chronic or paroxysmal atrial fibrillation in the absence of any other cardiac disease are at low risk of embolisation. In this group the risks of warfarin treatment outweigh the benefits and such patients should not be anticoagulated.

For those patients with non-rheumatic atrial fibrillation at high risk in whom anticoagulation is contraindicated or cannot be reasonably managed, the SPAF II study suggests that aspirin ( $325 \mathrm{mg}$ daily) is an alternative that may be effective in reducing the risk of cardiogenic embolism and stroke. Currently, aspirin cannot be recommended as an alternative to warfarin for the primary prevention of stroke in all patients with non-rheumatic atrial fibrillation, although the SPAF II study should clarify the relative merits of these two treatments.

All patients with non-rheumatic atrial fibrillation should now be carefully evaluated with a view to treatment with low intensity warfarin (or aspirin $325 \mathrm{mg}$ daily if warfarin is contraindicated) because such treatment will reduce the high annual risk of a potentially devastating and irreversible embolic stroke.

\section{We thank Mrs Jean Cunningham for secretarial assistance.}

1 Coulshed N, Epstein EJ, McKendrick CS, Galloway RW, Walker $\mathrm{E}$. Systemic embolism in mitral valve disease. Br Heart J 1970;32:26-34.

2 Cosgrift SW. Prophylaxis of recurrent embolism of intracardiac origin. JAMA 1950;143:870-2.

3 Stafforth JS, Gibberd MC, Ng Tang Fui S. Arterial embolism in thyrotoxicosis with atrial fibrillation. $\mathrm{Br}$ Med 1977;ii:688-90. 
4 Dunn M, Alexander J, de Silva R, Hildner F. Antithrombolic therapy in atrial fibrillation. Chest 1986; 89(suppl):68-81.

5 Bjerkland CJ, Orning OM. The efficacy of anticoagulan therapy in preventing embolism related to DC electrical conversion of atrial fibrillation. Am J Cardiol 1969;23: 208-16.

6 DiMarco JP. Further evidence in support of anticoagulant therapy before elective cardioversion of atrial fibrillation. J Am Coll Cardiol 1992;19:856-7.

7 Cerebral Embolism Study Group. Immediate anticoagulation of embolic stroke. A randomised trial. Stroke 1983; 14:668-76.

8 Koller RL. Recurrent embolic cerebral infarction and anticoagulation. Neurology 1982;32:283-5.

9 Ostrander LD Jr, Brandt RL, Kjelsberg MO, Epstein FH. of a total natural community, Tecumseh, Michigan. Circulation 1965;31:888-98.

10 Shaper AG, Pocock SJ, Walker M, Cohen NM, Wate CJ, Thompson AG. British Regional Heart Study: cardiovascular risk factors in middle-aged mert in 24 towns. $B$ Med J 1981;283:179-86.

11 Lake FR, McCall MG, Cullen KJ, Rusman DL, de Klerk tion. Aust NZ J Med 1989;19:321-6

12 Kannel WB, Abbott RD, Savage DD, McNamara PM Epidemiologic features of chronic atrial fibrillation: the Framingham Study. $N$ Engl J Med 1982;306:1018-22.

13 Kannel WB, Abbott RD, Savage DD, McNamara PM. Coronary heart disease and atrial fibrillation: The Framingham Study. Am Heart J 1983;106:389-96.

14 Wolf PA, Dawber TR, Thomas E, Kannel WB. Epidemiologic assessment of chronic atrial fibrillation and risk of logic assessment of chronic atrial fibrillation and risk of
stroke: The Framingham Study. Neurology 1978;28: stroke:

15 Reid DD, Brett GZ, Hamilton PJS, Jarret RJ, Keen H, Rose G. Cardiorespiratory disease and diabetes among middleaged male civil servants. Lancet 1974;i:469-74. fibrillation. Arch Neurol 1984;41:8-10.

17 Close JB, Evans DW, Bailey SM. Persistent lone atria fibrillation: its prognosis after clinical diagnosis. J Roy Coll Gen Prac 1979;29:547-9.

18 Evans W, Swan P. Lone auricular fibrillation. Br Heart 1954;16:189-94.

19 Petersen P, Godfredsen J. Embolic complications in

20 Gajewski J, Singer RB. Mortality in an insured population with atrial fibrillation. JAMA 1981;245:1540-4.

21 Kopecky SL, Gersh BJ, McGoon MD, et al. The natural history of lone atrial fibrillation. N Engl J Med 1987; 317:669-74.

22 Aronow WS, Gutstein H, Hsieh FY. Risk factors for thromboembolic stroke in elderly patients with chronic thromboembolic stroke in elderly patients with
atrial fibrillation. Am J Cardiol 1989;63:366-7.

23 Wolf PA, Kannel WB, McGee D. Duration of atrial fibrillation and imminence of stroke. The Framingham Study. Stroke 1983;14:664-7

24 Fuster V, Gersh BJ, Giuliani ER, Tajic AJ, Brandenburg RO, Frye RL. The natural history of idiopathic dilated cardiomyopathy. Am J Cardiol 1981;47:525-31.

25 Flegel KM, Shipley MJ, Rose G. Risk of stroke in nonrheumatic atrial fibrillation. Lancet 1987;i:526-9. Electrocardiographic findings among the adult population NH. Atrial fibrillation and mortality in an elderly popula-

16 Sherman DG, Goldman L, Whiting RB, Jurgensen K, Kaste $M$, Easton $D$. Thromboembolism in patients with atrial paroxysmal atrial fibrillation. Stroke 1986;17:622-6.

26 Pearie LA. Predictors of thromboembolism in atrial fibrillation: I. Clinical features of patients at risk. Ann Intern Med 1992;116:1-5.

27 Pearie LA. Predictors of thromboembolism in atrial fibrillation: II. Echocardiographic features of patients at risk. Ann Intern Med 1992;116:6-12.

28 Cerebral Embolism Task force. Cardiogenic brain embolism. Arch Neurol 1986;43:71-84.

29 Olsen TS, Skriver EB, Herning M. Cause of cerebral infarction in the carotid territory; its relation to the size and the location of the infarction and to the underlying and the location of the infarction and

30 Stein B, Fuster V, Halperin JL, Chesebro JM. Antithrombotic therapy in cardiac disease: an emerging approach based on pathogenesis and risk. Circulation 1989;80:1501-13.

31 Stroke Prevention in Atrial Fibrillation Investigators. Stroke Prevention in Atrial Fibrillation Study. Final results. Circulation 1991;84:527-39.

32 The Boston Area Anticoagulation Trial for Atrial Fibrillation Investigators. The effect of low-dose warfarin on the risk of stroke in patients with non-rheumatic atrial fibrillation. N Engl J Med 1990;323:1505-11.

33 Petersen P, Boyson G, Godfredsen J, Andersen ED, Andersen B. Placebo-controlled, randomised trial of warfarin and aspirin for prevention of thromboembolic complications in chronic atrial fibrillation: the Copenhagen AFASAK Study. Lancet 1989;i:175-9.

34 Connolly SJ, Laupacis A, Gent M, Roberts RS, Cairns JA, Joiner C. CAFA Study Investigators: Canadian Atrial Fibrillation Anticoagulation (CAFA) Study. J Am Coll Cardiol 1991;18:349-55.

35 Forfar JC. Prediction of haemorrhage during long-term oral coumarin anticoagulation by excessive prothrombin ratio. coumarin anticoagulation by

36 Bloomfield P, Wheatley DJ, Prescott RJ, Miller HC. Twelve year comparison of a Björk-Shiley mechanical heart valve with porcine bioprostheses. N Engl J Med 1991;324: 573-9.

37 Hammermeister KE, Henderson WG, Burchfiel CM, et al. Comparison of outcome after valve replacement with a bioprosthesis versus a mechanical prosthesis: initial 5 year results of a randomised trial. J Am Coll Cardiol 1987; 10:719-32.

38 Rahimtoola SH. Perspective on valvular heart disease: an update. J Am Coll Cardiol 1989;14:1-23.

39 Hirsch J. Is the dose of warfarin prescribed by American physisicians unnecessarily high? Arch Int Med 1987;147: 769-71.

40 Poller L. The effect of low dose warfarin on the risk of stroke in patients with non-rheumatic atrial fibrillation. $N$ Engl $J$ Med 1991;325:129-30.

41 Turpie AGG, Gunstensen J, Hirsh J, Nelson H, Gent $M$. Randomised comparison of two intensities of oral anticoagulant therapy after tissue heart valve replacement. Lancet 1988; i:1242-5.

42 Saour JN, Sieck JO, Mamo LAR, Gallus AS. Trial of different intensities of anticoagulation in patients with
dition prosthetic heart valves. $N$ Engl J Med 1990;322:428-32.

43 Levine MN, Raskob G, Hirsh J. Haemorrhagic complications of long term anticoagulant therapy. Chest 1989;95 (Suppl):265-365.

44 Cairns JA. Stroke Prevention in Atrial Fibrillation Trial. Circulation 1991;84:933-5.

\section{Neurological comment}

The dilemma of whether anticoagulation treatment reduces the likelihood of ischaemic stroke (and embolism generally) in patients with nonrheumatic atrial fibrillation, without causing unacceptable risk has been around for decades. At long last there are enough good data for reviewers like Dr Nolan and Dr Bloomfield to write something other than an expression of opinion based on anecdote and non-randomised comparisons. The risks of anticoagulants have been well enough appreciated but now the recent randomised trials give us some idea of the benefit of treatment, though an even better idea would come from a formal overview (or meta-analysis) of all the available randomised trials, particularly if the trialists were to pool individual patient data to examine risk and benefit in subgroups of interest (for example, the elderly and those with chronic fibrillation rather than paroxysmal fibrillation). Of course the costs must be considered as well. I suspect that providers and purchasers in the reformed NHS have very little idea of what anticoagulation really costs (what price a gastrointestinal haemorrhage?) and no idea at all about the cost of a stroke (what price granny's stroke if she can no longer look after the grandchildren to allow their mother to go out to work?). If treating 1000 fibrillating patients for a year does prevent about 25 of them from having a stroke, ${ }^{1}$ then 40 people must be treated to prevent one having a stroke during that period. "Is this worthwhile?" and "can we afford it?" are questions that providers and purchasers had better start working on fast, because I am certain that cardiologists and others will be anticoagulating a lot more patients, as Nolan and Bloomfield recommend. If aspirin is as effective or nearly as effective as anticoagulation then this treatment seems to be less risky and also more cost effective. This question re-emphasises just how extraordinarily important it is that recruitment into SPAF II and similar trials continues and that it is not assumed that for primary prevention of stroke in non-rheumatic atrial fibrilla- 